\title{
Mathematical Justification Ability: Students' Divergent and Convergent Process in Justifying Quadrilateral
}

\author{
Magita Danang Pamungkas*, Dwi Juniati, Masriyah \\ Mathematics Department, Universitas Negeri Surabaya, Surabaya, East Java, Indonesia. \\ * magitapamungkas16070785034@mhs.unesa.ac.id
}

\begin{abstract}
Justification is an important component in learning mathematics to optimize reasoning skill, understanding concepts and mathematical communication. This research is qualitative descriptive research because it aims to obtain a natural picture of the student's mathematical justification on the quadrilateral material. The subjects of this study consists of two students who have different learning style that are divergent and convergent. Data collection was done by giving related statements about quadrilateral material and used semi-structured questionnaire to justify their statement. Data was analysed based on mathematical justification indicator that were recognition, building-with, awareness. Based on the research result, the subject of divergent and convergent showed differences, those were not so far in the process of mathematical justification. The divergent subject analysed the mathematical situation through the form of a rule based on the apparent (concrete) information, but the convergent subject considered how the previous rule was formulated to search for new rules. It showed that in the learning process, justification could provide a picture of the students' thinking flow and explanation of the truth of a statement
\end{abstract}

Keywords- Justification Ability, Kolb Learning Style, Statement Of Quadrilateral.

\section{INTRODUCTION}

Mathematics contains of statements such as definitions, propositions, theorems, lemma and other statements in the form of logical sentences: implications, bi-implications, negations, or quantor sentences. It is required a process of verification to find the truth of the mathematical statements. Harel and Sowder [1, 2] use the term proof to explain justification. Proving is the process employed by an individual (or community) to remove doubts about the truth of an assertion. This process contains two sub-processes: Ascertaining (in which individuals remove their own doubts) and persuading (in which individuals remove others' doubts). Then, Harel and Sowder pointed out that they used 'proving' with the wider meaning of justification [1, 2]. In a broad sense, proving can even be regarded as justification $[3,4,5$, 6]. In addition, according to Staples et al. [7] "Justifying is the act of developing arguments to demonstrate the truth (or falsehood) of a claim using mathematical forms of reasoning". As a disciplinary practice, justification has many purposes: it is used to validate claims, provide insight into a result or phenomenon, and systematize knowledge [5]

Dreyfus et.al [8] and Harel R [9] based on the results of their research explain that the processes of student justification are through several stages such as recognition, building-with, and awareness. Students are expected to provide explicit reasons based on prior knowledge. They have to be able to prove the truth to a statement which includes the stage of recognition in the justification process. After recognizing some elements of prior knowledge, students are expected to justify a statement which in the justification process includes the building-with stage. Besides, students can make a clear summary to answer the truth of the statement included awareness stage in the justification process. The processes of justification that have been done by students in validating a statement, can describe the thinking flow of the students, and the explanation why a statement is true. In this research, the researchers use 3 indicators to know the process of student justification on the quadrilateral material based on the research result of Harel $\mathrm{R}$ and Kidron I [9] namely recognition is the ability to recognize previous knowledge relevant to the mathematical situation related to quadrilateral material. Building-with is the ability to apply prior knowledge for the purpose of mathematical justification processes related to quadrilateral material. Awareness is the ability to show a clear summary to answer the truth of mathematical statements on quadrilateral material.

Based on the results of Pantaleon et.al [10], that in the proving of geometry, the subject explains what is understood, presents the idea in the form of drawing and symbols, and explains the content/meaning of a representation accurately and clearly, but the subject cannot convey the argument systematically and logically. Basically, The ability of students justification may vary. This is possible because of the differences in learning styles that students have. Learning styles are a different way that we prefer to engage in thinking, processing, and understanding of information [11, 12] Students have their own preferred way of absorbing and processing information by connecting parts of knowledge such as concepts and ideas, and existing knowledge to make a conclusion of the truth of a statement. The learning style used in this study is the learning style developed by David Kolb 
$[13,14]$ which is one of the learning styles of divergent and convergent. Kolb's learning style is chosen because this learning style can be interpreted as mathematical learning styles and emphasizes more on the study of information processing to gain new knowledge [15].

The purpose of this research was to describe the justification profile to the qudrilateral material of junior high school students with divergent and convergent learning style. The results of this study were expected to be used as a reference for other researchers who conduct research relevant to this research.

\section{METHOD}

This research was descriptive qualitative to obtain a natural description of mathematical justification for divergent and convergent students learning style in rectangular material. The research was conducted in seventh grade at SMP Negeri 4 Probolinggo in the 2017/2018 academic year specifically in second semester. The subjects are consisted of two junior high school students that each represented two learning styles (divergent and convergent) with equivalent mathematical abilities shown by mathematical test results that were not much different, i.e. by the difference in subjects' values $\leq 5$ and the teacher's recommendation.

The data collection was done by giving a problem to the subjects containing two statements related to the quadrilateral concept including the identification of the area of the quadrilateral. Students were required to provide justification (true or false) to the statement and the reasons. The answers of students obtained written descriptive data of the ability of divergent and convergent student justification. Semistructured interviews were conducted on two subjects to investigate a more in-depth process of student justification relating to the reasons given to the test results. The assignment analysed was as follows:

A.1. On a square, if the diagonal length of a square is extended twice, the area will be doubled from the original one.

A.2. A photo of $40 \mathrm{~cm} \times 50 \mathrm{~cm}$ will be pasted to a piece of cardboard. If the right, left, top and bottom side of the photo have $5 \mathrm{~cm}$ remaining, so that, the cardboard area are uncovered by the photo is half of the photo area.

The data analysed is based on the indicators used by the researchers to know the process of student justification, those are stage (1) recognition, (2) building-with, (3) awareness

\section{RESULT}

Questionnaires of learning style were given to student in seventh grade at SMP Negeri 4 Probolinggo. It was obtained information that 7 students were divergent and 4 students were convergent. Based on the results of the questionnaire, two male students were chosen, had different learning styles (convergent and divergent) and had equivalent mathematical ability based on mathematics ability test and teacher recommendation for research subject.

\section{A. Mathematical Justification of Divergent Subject}

The divergent subject was still wrong in proving the truth of a statement related to the quadrilateral concept. Based on the results of the answer, the subject was still descriptive, minimal informative in showing the truth of a statement. Here is a Figure 1 that shows the results of the mathematical justification test for Divergent subject.

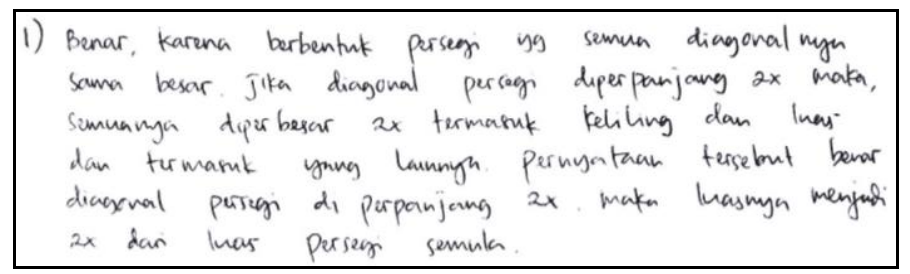

Figure 1: The Example of Mathematical Justification of Divergent Subject

Based on the results of the justification test, the subject justified the statement of the wrong value only based on the assumption about the property of a square that had the same diagonal length (recognition). He assumed that if the square diagonal was extended twice then everything would be enlarged twice including the circumference and area (buildingwith). So, he concluded that true if the square diagonal was extended two times then the area became two times from the original square area (awarenes).

In addition to one of the next example seen in Figure 2 below this.

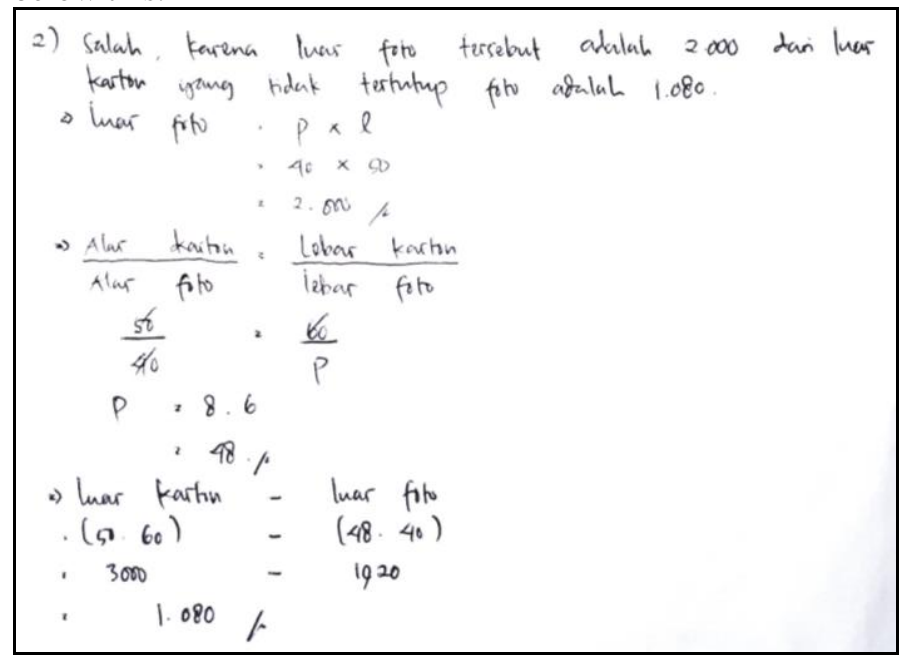

Figure 2: The example of mathematical justification of divergent subject

Based on the results of the next justification test, the subject tried to justify the true value statement by using a formula of comparison and area (recognition) to determine the truth of the statement about the area of the rectangle. By that, the subject recognized the relevance of the element of knowledge: 
E1: The area of the rectangle is the same as the product of the length and with, and given by the expression:

\section{$L=p \times l$}

E2: Side comparison that is proportional between cardboard and photo

The subject initially calculated the area of the photo and the cardboard area by searching cardboard length and width first by using the comparison formula. Furthermore, to find the area of cardboard that was not closed to the photo, he calculated the area difference of cardboard and photo (building-with). So, the subject concluded that it was wrong if the ratio of cardboard area that was not covered by photo was half of the photo area (awareness).

\section{B. Mathematical Justification of Convergent Subject}

The convergent subject could be said to be true in proving the value of a statement related to the quadrilateral concept. Based on the results of the answer, the subject used counter example and formula rules in showing the truth of a statement. Here's Figure 3 that shows the results of the mathematical justification test for Convergent subject.

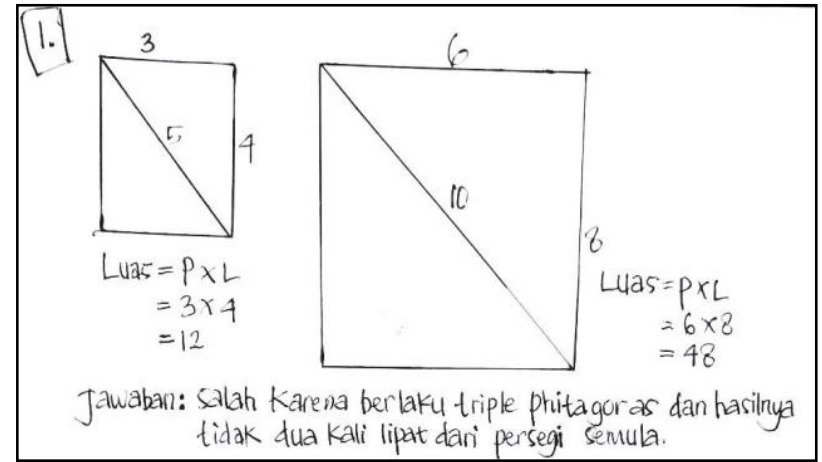

Figure 3: The example of Mathematical Justification of Convergent Subject

Based on the results of the justification test, the subject justified the incorrect statement based on counter example that the square is a specific form of rectangle so that the pythagorean theorem can be used and based on the rules of the area formula (recognition). By that, the subject recognized the relevance of the element of knowledge:

A1: Rectangle consists of two right triangles, so pythagorean theorem applies:

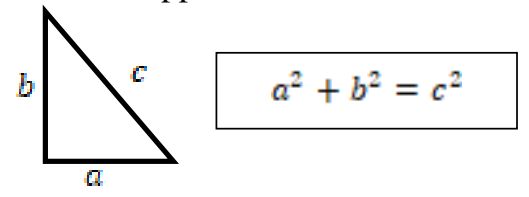

A2: The area of the rectangle is the same as the product of the length and width, and given by the

expression: $L=p \times l$
So from a counter example, it was obtained a rectangle and then searched the area of the rectangle (building-with). Finally, he concluded that it was wrong if the diagonal of square was extended two times then the area become two times from the original square area (awareness).

In addition to one of the next example seen in Figure 4 below this.

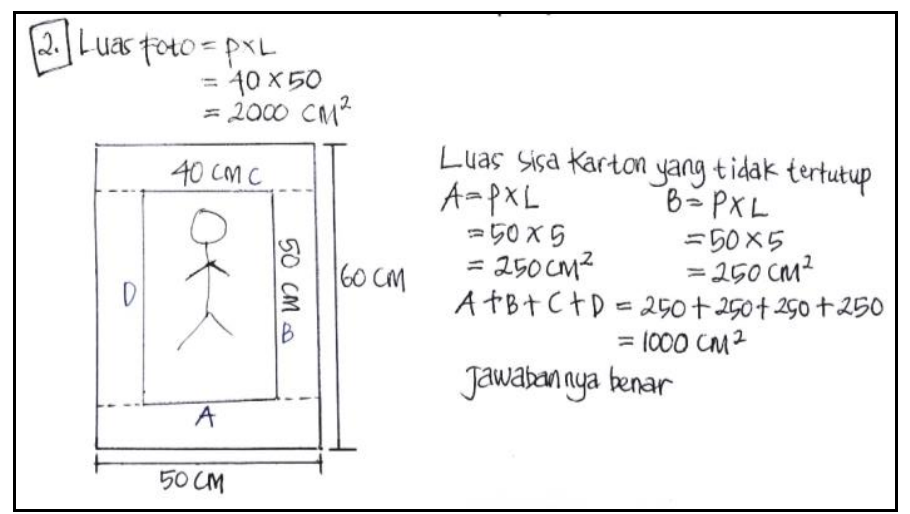

Figure 4: The Example of Mathematical Justification of Convergent Subject

Based on the results of the next justification test, the subject tried to justified a true value statement by illustrating it through an image and used a rectangular area formula (recognition) to determine the truth of the statement about the area of the quadrilateral. By that, the subject recognized the relevance of the element of knowledge:

A1: The area of the cardboard is uncovered in parts of the area of the photo.

A2: The area of the rectangle is the same as the product of the length and width, and given by the expression:

$$
L=p \times l
$$

The subject calculated the area of the photograph first and then found the length and width of the cardboard by adding 5 $\mathrm{cm}$ on each side of the photo (illustrating it through the image). Furthermore, to calculate the area of the cardboard that was not covered by photo, the subject calculated the remaining area of each right, top, left, and bottom of the cardboard that was not covered by a cardboard (buildingwith). So from that, the subject compared the remaining area of the cardboard that was not covered with the area of the photo. Finally, the subject concluded it was true that the ratio of cardboard area that was not covered by photograph was half of the photo area (awareness).

\section{DISCUSSION}

The divergent and convergent subjects in justifying a statement was not much different. According to Kolb [13,14], subjects with divergent learning styles in solving a problem especially to prove the truth of a statement, they tend to be careful and considerate so they can have imagination and 
creative abilities in connecting information with other information. But from the results of this study divergent subject only assumed in analysing the mathematical situation through the forming of a rule based on information that appears (concrete) and without considered other things. So, the justification was descriptive. Besides, it provided less information. The situation happened because they were not accustomed to justifying their solution. [16]

The characteristics of the convergent subjects learning style can be described like for example in solving a problem, especially to prove the truth of a statement, they looked at the concept as a tool for building new ideas and approaches. The subjects used theory in making decisions and developed strategies in solving problems $[13,14]$. It was also concluded from the results of this study that the convergent subject provided a clear explanation for the truth of a statement by using the concept of triple Pythagoras and the rectangle area although basically it was not suitable to be used in one of the tasks justification given

\section{CONCLUSION}

Based on the result, it can be concluded that the divergent and convergent subjects showed that they were not much different in the process of mathematical justification. In examining the validity of an argument, the divergent subject analysed the mathematical situation through the formation of a rule only on the basis of apparent (concrete) information without regarding to other cases, whereas the convergent subject considered the preceding formation of rules to seek new rules through concepts which exists.

\section{ACKNOWLEDGMENT}

This research cannot be separated from the help and support from SMP Negeri 4 Probolinggo so that the authors are grateful to the headmaster and the seventh grade math teacher which had helped by giving big contribution to the research activities. The opinions expressed herein do not necessarily reflect the position, policy, or endorsement of the supporting agency.

\section{REFERENCES}

[1] G. Harel and L. Sowder, "Students' proof schemes", Research on Collegiate Mathematics Education, vol.3, pp. 234-283, 1998.

[2] G. Harel and L. Sowder, Toward comprehensive perspectives on the learning and teaching of proof. In F. Lester (Ed.), Second handbook of research on mathematics teaching and learning, Charlotte, NC: Information Age Publishing, 2007, pp. 805-842.

[3] D. L. Ball and H. Bass, "Making Mathematics Reasonable in School. In Kilpatrick, J., Martin, W. G., Schifter, D. (Eds.), “A Research Companion to Principals and Standards for School Mathematics, 2003, pp. 27-44

[4] J. R. Back, L. Mannila, and S. Wallin, Student Justifications in High School Mathematics, Proceedings of CERME 6, 2006.

[5] M. Staples and J. Bartlo, Justification as a Learning Practice: Its Purposes in MIddle Grades Mathematics Classrooms, CRME Publications, 2010.

[6] L. Mannila and S. Wallin, Promoting Students Justification Skills Using Structured Derivations. To be presented at ICMI 19, Taiwan, 2009.

[7] M E. Staples, J. Bartlo, and E. Thanheiser, "Justification as a teaching and learning practice: Its (potential) multifacted role in middle grades mathematics classrooms", The Journal of Mathematical Behavior, vol. 31, no. 4, pp. 447-462, 2012.

T. Dreyfus, R. Hershkowitz, and B. B. Schwarz, "Abstraction in context II: The case of peer interaction", Cognitive Science Quarterly, vol.1, pp. 307-358, 2001.

[9] R. Harel and I. Kidron, "Defining The Need For Justification In Processes of Contructing Justification", Psychology of Mathematics Education, vol.3, no. 1, pp. 1-8, 2013.

[10] K. V. Pantaleon, D. Juniati, A. Lukito, and K. Mandur, "The written mathematical communication profile of prospective math teacher in mathematical proving", Journal of Physics, 2018.

[11] B, DePorter and M. Hernacki, Membiasakan belajar nyaman dan menyenangkan. Indonesian Handbook Quantum Learning, Bandung: Kaifa, 2003

[12] A. SIrIn and A. Güzel, "The Relationship between Learning Styles and Problem Solving Skills among College Students", Educational Sciences: Theory \& Practice, vol. 6, no.1, pp 256257,2006

[13] D. A. Kolb, R. E. Boyatzis, and Mainemelis, Experential Learning: Experience As a Source Of Learning and Development. Cleveland: Case Western Reserve University, 1999.

[14] A. Y. Kolb and D. A. Kolb, The Kolb learning Style InventoryVersion 3.1, Technical Specification, 2005.

[15] J. Knisley, A four-stage model of mathematical learning. Mathematic Educator, Johnson City: Department of Mathematics of East Tennessee State University, 2002.

[16] T. Dreyfus, "Why Johnny Can't Prove", Educational Studies in Mathematics, vol. 38, no. 1-3, pp. 85-109, 1999. 